\title{
PERFORMANCE ASSESSMENT OF TARIFF-BASED AIR SOURCE HEAT PUMP LOAD SHIFTING IN A UK DETACHED DWELLING FEATURING PHASE CHANGE-ENHANCED BUFFERING
}

\author{
Nicolas J Kelly ${ }^{1 *}$, Paul G Tuohy ${ }^{1}$, Adam Hawkes ${ }^{2}$ \\ ${ }^{1}$ Energy Systems Research Unit, Department of Mechanical and Aerospace Engineering, \\ University of Strathclyde, 374 Cathedral St, Glasgow, UK, G1 2TB \\ ${ }^{2}$ Centre for Environmental Policy, Imperial College, Imperial College London, South Kensington \\ Campus, London, UK, SW7 1NA \\ *Corresponding author: nick@esru.strath.ac.uk
}

\begin{abstract}
Using a detailed building simulation model, the amount of thermal buffering, with and without phase change material (PCM), needed to time-shift an air source heat pump's operation to off-peak periods, as defined by the UK 'Economy 10' tariff, was investigated for a typical UK detached dwelling. The performance of the buffered system was compared to the case with no load shifting and with no thermal buffering. Additionally, the load shifting of a population of buffered heat pumps to off-peak periods was simulated and the resulting change in the peak demand on the electricity network was assessed. The results from this study indicate that $1000 \mathrm{~L}$ of hot water buffering or $500 \mathrm{~L}$ of PCM-enhanced hot water buffering was required to move the operation of the heat pump fully to off-peak periods, without adversely affecting the provision of space heating and hot water for end user. The work also highlights that buffering and load shifting increased the heat pump's electrical demand by over $60 \%$ leading to increased cost to the end user and increased $\mathrm{CO}_{2}$ emissions (depending on the electricity tariff applied and time varying $\mathrm{CO}_{2}$ intensity of the electricity generation mix, respectively). The study also highlights that the load-shifting of populations of buffered heat pumps wholly to off-peak periods using crude instruments such as tariffs increased the peak electrical loading by over $50 \%$ on the electrical network rather than reducing it and that careful consideration is needed as to how the load shifting of a group of heat pumps is orchestrated.
\end{abstract}

Keywords: load shifting; demand side management; domestic; heat pump; phase change material; simulation.

\section{Introduction}

The UK has committed itself to radically reducing its greenhouse gas (GHG) emissions over the coming decades, with a specific target of an $80 \%$ reduction by 2050 [1]. Key to achieving this goal lies in decarbonising the space and water heating demands of the 26 million dwellings that comprise the UK domestic sector [2]. Housing accounts for over 30\% of the UK's final energy consumption [3] and around $38 \%$ of its greenhouse gas (GHG) emissions [4].

The widespread uptake of heat pumps, coupled with central electricity generation from nuclear and renewable sources is often cited as a means to decarbonise domestic heating (e.g. [5], [6]). However, as the vast majority of UK dwellings likely to be extant in 2050 are already constructed [7], then a radical reduction in domestic GHG emissions will require a widespread heat pump retrofit programme. Air source heat pumps (ASHPs) have the potential to act as a direct replacement for the fossil-fuelled boilers commonly found in UK housing, though their control needs to be slightly different and heat emitters need to be resized to account for the lower flow temperatures delivered by heat pumps [8]. The (relatively) low cost of installation and the lack of a requirement for ground works makes ASHPs a more feasible mass retrofit proposition than ground source heat pumps (GSHP).

A consequence of significant numbers of ASHPs being retro-fitted into the housing stock could be substantially increased electrical load in the low voltage (LV) distribution system (e.g. [9]) leading to problems such as voltage dips and cable overloading, and potentially the need for expensive network reinforcement. One means to avoid this scenario is to shift heat pump electrical demand to off-peak periods such as the early morning, late evening or the middle of a typical working day, when 
domestic electrical demand is lower. However, this could have an impact on the delivery of adequate indoor temperatures and the provision of hot water. Effective shifting of heat pump operation requires that the manipulation of operating times is achieved with the minimum of inconvenience to the end user. An appropriate means to deliver effective load shifting is through the provision of sufficient thermal buffering to temporally decouple the operation of the heat pump from the space heating and hot water demands.

\subsection{Review}

There are many examples of electrical heating or cooling load shifting in the literature. For example, Moreau [10] studied load shifting in populations of hot water heating loads, indicating that care is required in how load shifting was undertaken or there was a risk of exacerbating rather than reducing the demand on the network. In a study focused on wind energy, Callaway [11] assessed the potential for manipulation of large populations thermostatically controlled loads to follow variable renewable generation. Wang et al [12] analysed the potential for load shedding in a large population of many thousands of unbuffered domestic heat pumps by manipulating of the space heating set point. Focusing specifically on heat pumps, Hewitt [5] argues that their use with thermal storage could be a useful means of load management in an electricity system with increasing quantities of renewable energy generation. However, as the paper is strategic in focus, the author does not undertake any specific analysis of the load shifting potential nor of the size of thermal store required.

Whilst the aforementioned studies on large populations of devices provide useful insight into the scope for domestic load management, they do not truly examine the potential effect on the end user in terms of comfort or provision of hot water. This either is because the thermal model employed is necessarily simplified (due to the large number of loads covered in the study) or because only one aspect of heating is covered (i.e. space or water heating). Proper assessment of the effect of thermal load shifting on the end user typically requires the use of a more detailed model of the building.

Studies focused on the implications of load shifting at the level of the individual dwelling, with detailed modelling of the impact on internal conditions are less common in the literature. Bagdanavicius and Jenkins [6] use a building simulation tool to estimate the potential extra electrical load on the supply network from domestic heat pumps. They indicate that significant load shifting would be required to reduce demand peaks, though the authors do not explicitly model any load shifting nor its impacts. Hong et al, ([13], [14]) examined the potential for flexible operation of air source heat pumps (ASHP) retro-fitted into UK dwellings when constrained by the need to deliver hot water and thermal comfort. They found that shifts in heat pump operating times of up to 6-hours were possible, but only with the addition of significant quantities of hot water thermal buffering (up to $500 \mathrm{~L}$ ) coupled with extensive improvements to the building fabric: in their paper, the authors do not explicitly follow any load shifting strategy and instead use a sensitivity analysis. Further, the authors do not fully explore the implications of load shifting on the heat pump's energy and environmental performance. Arteconi et al [15] investigated the use of buffering in detached dwellings insulated to 1990 UK building standards with both under floor and radiator-based heating systems. They calculated that up to $800 \mathrm{~L}$ of buffering would be required to deliver only 1-hour of load shifting. In this study, the authors only analyse sensible thermal buffering. Hong et al pointed out the difficulty of accommodating large hot water tanks; particularly as new build UK housing is high-cost reducing in size [16]. More volumetrically efficient thermal buffering (e.g. PCM-enhanced buffering) is therefore beneficial, as it would take up less valuable living space within a dwelling.

\subsection{Objectives}

By simulating the performance of a 'typical' UK family dwelling [17] equipped with a heat-pumpbased heating system, the contribution of this paper is to address some of the gaps in the knowledge relating to domestic heat pump load shifting. Firstly, the volume of thermal storage (with and without PCM) required to effectively load shift heat pump entirely to off-peak periods, as defined by the UK economy 10 tariff [18], is assesed; this is the volume of storage required to achieve shifting without affecting end-user comfort and hot water delivery. Secondly, the impact of load shifting on 
the heat pump's energy and environmental peformance is assessed along with an assessment of the effect on running costs. Finally, to assess the potential impact on electrical demand, an example is presented where a population of heat pumps are load shifted to timings dictated by the UK the Economy 10 tariff.

\section{Modelling}

The typical UK family dwelling was developed as an integrated ESP-r model [19], which features both the dwelling, the heat pump and its associated heating system. The ESP-r building simulation tool, allows the energy and environmental performance of the building and its energy systems to be determined over a user defined time interval (e.g a day, week, year). The tool explicitly calculates all the all of the energy and mass transfer processes underpinning building performance. These include: including conduction and thermal storage in building materials, all convective and radiant heat exchanges (including solar processes), air flows, interaction with plant and control systems. To achieve this, a physical description of the building (materials constructions, geometry, etc.) is decomposed into thousands of 'control volumes'. In this context, a control volume is an arbitrary region of space to which conservation equations for continuity, energy (thermal and electrical) and species can be applied and one or more characteristic equations formed. A typical building model will contain thousands of such volumes, with sets of equations extracted and grouped according to energy system. The solution of these equations sets with real time series climate data, coupled with control and occupancy-related boundary conditions yields the dynamic evolution of temperatures, energy exchanges and fluid flows within the building and its supporting systems. The validity of the ESP-r tool is reviewed in [20].

The focus of the work presented here is therefore the application of the ESP-r tool, rather than development of algorithms or new functionality: all of the models used are already available in the general release of ESP-r. The algorithms underpinning the key heating system components referred to later in this paper are documented in more detail elsewhere: air source heat pump [21], the buffering and hot water storage tanks [22] and radiators and controls [23].

\subsection{Model Details}

\section{Dwelling}

The dwelling analysed in this paper represents a typical UK detached house [17]. This type of residence comprises around 30\% of the existing UK housing stock [2] and is large enough to accommodate the volume of thermal buffering indicated by Hong et al [14] and Arteconi et al [15] as required for load shifting. The dwelling model is shown in Figure 1. The dwelling has a floor area of $136 \mathrm{~m}^{2}$ spread over an upper and ground floor. The building features three main spaces (zones): a loft zone and two composite zones describing (respectively) the areas of the dwelling hosting active occupancy such as the living room and kitchen and those areas that have low occupancy rates or that are occupied at night such as bathrooms and bedrooms, respectively. The key characteristics of the model are shown in Table 1; this form of model captures the pertinent thermodynamic characteristics of the building's performance and has been deployed successfully in other studies, e.g. [24].

Figure 1

This necessity of thermally upgrading the building fabric in parallel with the installation of the heat pump is illustrated in the findings of Hong et al. [13, 14], who indicated that without thermal improvements, the volume of thermal storage required for load shifting becomes impractical. Consequently, The fabric of the dwelling was subject to a pragmatic and cost-effective energy 
efficiency retrofit ${ }^{1}$. The external cavity wall was filled with $60 \mathrm{~mm}$ of insulation. Thermal bridging in the fabric was accounted for by adding a further $10 \%$ to the external wall U-values over and above the values derived from the constructions of Table 1. A total of $300 \mathrm{~mm}$ of insulation was added between the loft space and the occupied areas of the building. A further $300 \mathrm{~mm}$ of insulation was added between the occupied area of the building and the void under the floor space. The building is assumed to have pre-existing double glazing, the U-value used is typical of pre-2002 UK double glazing with a UPVC frame $[25,26]$

\section{Table 1}

The average air change rate used in the model is 0.5 air-changes-per-hour, which is also the value typically applied in standard dwelling assessments [26]; this value is consistent with air tightness values measured in similarly thermally upgraded dwellings [27]. The air change rate represents the average volume of outside air entering the dwelling under normal operating conditions and comprises the construction infiltration plus the occupant's use of trickle vents, windows and doors. Additionally, the infiltration model also accounts for increased window opening as indoor temperatures rise, infiltration increased to mimic the effect of window opening in order to prevent overheating.

The dwelling was assumed to be occupied by a family of four (two adults and two children) with active weekday occupancy between $07.00-09.00 \mathrm{hrs}$ and $17.00-23.00 \mathrm{hrs}$. The occupants were assumed to be sleeping between $23.00-07.00 \mathrm{hrs}$. Outside of these periods, the house was unoccupied. During weekends, active occupancy was assumed to be between 08.00-10.00 and 16.00$24.00 \mathrm{hrs}$, with the family sleeping between 24.00 to 08.00 and engaged in other activities away from the home between 10.00 and 16.00; the weekday and weekend occupancy profiles are derived from UK time-use survey data [28].

\section{Air Source Heat Pump}

The ASHP supplies the space and water heating needs of the dwelling. The dynamic air source heat pump model (ASHP) used in these simulations was calibrated and verified using field trail data as described by Kelly and Cockroft [21]. The version of the model used here has a nominal 10kW of thermal output and nominal coefficient of performance of approximately 2.8. In common with other ESP-r systems component models, the ASHP algorithm is dynamic and explicitly accounts for thermal inertia, the variation in the return hot water temperature and ambient air temperature and their impact on heat output and compressor power consumption. The model also accounts for impact of defrosting of the evaporator coils as a function of outdoor relative humidity and air temperature. Illustrative performance output from the model is shown in Figure $2 \mathrm{a}$, which shows the variation in ASHP heat output and coefficient of performance with external temperature. AS would be expected, both COP and heat output deteriorate as ambient temperature drops. The spread of these values is due to the dependence of both on the ambient and the return water temperature from the heating system. For example, when the heat pump starts up, the COP and heat output is initially high as the heating system is cool and the temperature difference across the heat pump is at its lowest. Both the COP and heat then drop as the heating system comes up to temperature. This performance mirrors the performance characteristics seen in UK field trials [21].

Figure 2a

Key parameters and equations used with the model are shown in Table 2.

Table 2

\section{Systems Model}

The heat pump model described above was integrated with other ESP-r systems component models to form a systems network; these in turn were linked into the building model to form an integrated

\footnotetext{
${ }^{1}$ In principle, it would be possible to upgrade a dwelling to passive house standards [29]; however this would require extensive building modifications in order to drastically reduce the U-value of external surfaces along with infiltration of outside air and such dramatic modifications could be prohibitively expensive (e.g. [30]).
} 
building and systems model. The unbuffered and buffered systems networks developed for these simulations are illustrated in Figures $3 a$ and $3 b$, respectively. These were applied to assess the performance of the heat pump with no load shifting (reference case) and with its operation set-back to off-peak periods, respectively.

Note that, all of the other component models (e.g. pumps, piping radiators) used in the systems networks are derived using the same control volume approach that was used in the heat pump model and which is also applied in the modelling of the building. All of the components shown are available in the standard release of ESP-r.

Figure $3 a$

Figure $3 b$

In the unbuffered system model, the ASHP supplies hot water to the heating circuit directly (a configuration seen in many UK installations e.g. [21]; the piping, valves and radiators of the heating circuit are modelled explicitly using existing, validated ESP-r models [26]. The model of the radiators, like other ESP-r components is dynamic, with its heat output calculated as a function of the radiator surface areas, hot water inlet temperature and the surrounding building (zone) air and radiative temperatures. The radiators have been sized to operate at a nominal flow temperature of $50^{\circ} \mathrm{C}$ from the heat pump. However, as is shown later in Figures 9 and 10, as the dynamic performance of the heating system is simulated, the actual temperature of water delivered to the radiators and consequently their heat output varies with time.

\section{Domestic Hot Water Tank and Hot Water Draws}

The heat pump also services the $200 \mathrm{~L}$ domestic hot water (DHW) tank via an internal hot water heating coil - a common set-up in the UK. The ESP-r tank model used to represent the DHW tank comprises a large number of finite volumes (approximately 100), for each of which an explicit energy balance equation is derived; the ESP-r tank model is described in detail by Padovan and Manzan [22]. The model explicitly accounts for stratification. Heat is supplied from the heat pump via an indirect heating coil, and hot water is drawn directly from the tank. The heat loss from the tank is calculated based on an assumed heat loss coefficient of $1 \mathrm{~W} / \mathrm{m}^{2} \mathrm{~K}$ : this is typical of the insulation levels found on modern UK water tanks.

The time-varying hot water draw from the DHW tank was calculated based on a stochastic, highresolution algorithm developed by Jorden and Vagen [31]; this calculates hot water draws at a 1minute resolution. A nominal daily hot water demand of $120 \mathrm{~L} /$ day is assumed (consistent with the hot water use of a family of four [32]). The nominal percentage of the total daily draw taken at different periods of the day is defined along with four characteristic draw types, representing draws from basins, hot water appliances such as washing machines, draws attributable to showers and draws assoctated with baths. Each of these draw types is assigned a nominal draw flow rate and standard deviation along with the nominal percentage of the daily draw attributable to that type (Table 3).

Figure 4

Table 3

\section{Buffer Tank}

In the buffered system, a circulation pump transfers the heat stored in the buffer tank to the heating and hot water circuits. Like the DHW tank model, the buffer tank model explicitly accounts for stratification and the heat is supplied from the heat pump via an indirect heating coil. The systems 
variants shown could be retro-fitted into many existing UK dwellings and was employed in recent UK heat pump trials [33]. The buffer tank is supplied with heat from the ASHP via a hot water heat exchanger located in the bottom portion of the tank. Hot water for the heating circuit and DHW (Figure 5) is taken from the top of the tank and the cold-water feed is supplied to the lower portion of the tank. The buffer tank can be augmented with variable numbers of cylindrical, encapsulated phase change modules (as shown in Figure 5) and so can be used to model hot-water-only thermal buffering as well as hot water buffering incorporating different percentages (by tank volume) of PCM. The model explicity tracks the phase state of the PCM modules. As with the DHW tank, heat loss coefficient of $1 \mathrm{~W} / \mathrm{m}^{2} \mathrm{~K}$ was assumed.

Figure 5

\section{System Control}

The heating system control strategy was derived from heat pump field trials and monitoring studies $[23,33]$ and differed depending upon whether a buffer tank was present. With a buffer tank, the ASHP was operated in an attempt to maintain the buffer temperature between 50 and $55^{\circ} \mathrm{C}$, (on/off control with a $10^{\circ} \mathrm{C}$ dead band). The circulating pump then provided heat to the hot water tank and heating system if there was a requirement for either space heating or hot water. Ideally, the DHW tank was ideally maintained between $43-45^{\circ} \mathrm{C}$ and the space temperatures within the living zone were ideally to be maintained between 19.5 and $22.5^{\circ} \mathrm{C}$, both using on/off control with a dead band. In additionally to control of the ASHP based on space temperatures, the flow to the radiators in each individual zone is modulated using a valve component to maintain space temperatures, where possible, between 19.5 and $22.5^{\circ} \mathrm{C}$; this mimics the action of thermostatic radiator valves (TRVs).

As is common in UK heating systems, priority was given to hot water - the hot water priority valve diverts all of the heat supply to the hot water tank if this was below the set point temperature. Only when the hot water tank was between 43 and $45^{\circ} \mathrm{C}$ was heat supplied to the heating circuit. With the unbuffered system, the ASHP was controlled directly in an attempt to maintain the conditions indicated previously in the DHW tank and living space.

Note that in UK boiler-based hot water systems, the convention is that hot water is maintained at $60^{\circ} \mathrm{C}$ to prevent the growth of Legionella bacteria [34]. However, this is an inefficient practice as the Legionella threat can be removed by occasionally raising water storage tank temperatures above $60^{\circ} \mathrm{C}$ [35]. In the simulations that follow the hot water tank temperature is raised to $60^{\circ} \mathrm{C}$ by an electric heater once every 10 days at an energy cost of approximately $180 \mathrm{kWh}$ per annum.

The on-off control used with the heating system represents the type of heating control commonly employed in millions of UK dwellings and the recent UK Energy Saving Trust field trial of domestic heat pumps [33].

\section{Methodology}

Using the ESP-r model described, a series of simulations were run to

- determine the size of thermal buffer required to shift the heat pump operation wholly to offpeak periods (as defined by the Economy 10 tariff [18]) in an extreme winter week;

- assess the overall annual performance of the load-shifted heat pump; and

- gauge the impact of heat pump load shifting using the Economy 10 tariff on the electrical demand of a group of dwellings.

The specific details of each of these simulations is described in the following sections.

\subsection{Buffer Sizing and PCM-Enhanced Buffering Simulations}


In order to determine the size of the buffer tank required for the load shift, the performance of the dwelling with heat pump was simulated over a cold winter week in January ${ }^{2}$, in which the minimum ambient temperature was $-2.1^{\circ} \mathrm{C}$, the maximum temperature was $9.5^{\circ} \mathrm{C}$ and the mean temperature was $3.4^{\circ} \mathrm{C}$. These conditions are characteristic for the UK's maritime climate in winter. The cold ambient temperatures represents an extreme case, when the heat pump COP will be low, and ensures that the load-shifted heat pump and buffer can adequately meet hot water and space heating demands throughout the year.

To implement the load shift, the heat pump was constrained to operate only in off-peak periods as defined by the UK economy 10 tariff, which offers lower electricity prices between the times of 00.00-05.00hrs, $13.00-16.00 \mathrm{hrs}$ and $20.00-22.00 \mathrm{hrs}$. Constraining the heat pump to operate within these hours means that other than the period 20.00-22.00hrs, it was operated when the house was unoccupied or when the occupants were asleep. The hot water circulation pump (Figure 2) could draw heat from the buffer tank at any time between the hours of $06.00-09.00 \mathrm{hrs}$ and $16.00-23.00 \mathrm{hrs}$, i.e. corresponding to the periods of active occupancy within the dwelling plus one-hour of preheating at the beginning of each period, controlled using a timer.

In successive simulations, the volume of the thermal buffer was varied from 200-1200 L in $100 \mathrm{~L}$ increments. In addition, the percentage of PCM in the thermal buffer (by volume) was varied from $0 \%$ up to $70 \%$ in $10 \%$ increments; above $70 \%$ PCM, the space remaining in the tank for the charging heat exchanger becomes too restrictive. This approach enabled the hot-water-only buffer size and the PCM-enhanced buffer size required for effective load shifting to be determined from the same group of simulations.

The PCM used in these simulations was a commercially available inorganic hydrated salt with the characteristics shown in Table 4; this material was selected as the best-fit match for the operating characteristics of the heat pump, enabling the buffer to operate in the phase change range and making best use of the material's latent heat.

Table 4 [36]

For the purposes of comparison, the performance of the unbuffered heat pump was simulated with no load shifting imposed (the reference case). The heat pump was connected directly to the heating circuit (Figure 1) and the hours of possible heat pump operation were set to $06.00-09.00 \mathrm{hrs}$ and 16.00-23.00hrs, with the heat pump free to operate at any point within the time periods. Note that these times also coincide with the UK's morning and evening peaks of electrical demand between 08.00-09.00hrs and 17.00-18.00hrs respectively [37].

The times in which the heat pump is allowed to operate for both the load-shifted and reference cases are shown in Figure 6.

\section{Figure 6}

The key performance criteria to be extracted from the simulation results were that 1 ) the living zone dry resultant temperatures should not fall below $18^{\circ} \mathrm{C}$ and 2) hot water temperatures should be kept above $40^{\circ} \mathrm{C}$ during occupied hours.

A dry resultant temperature of $18^{\circ} \mathrm{C}$ is towards the lower end of acceptable thermal comfort as defined by Fanger [38]. Note that a dry resultant temperature ( $50 \%$ mean radiant temperature, $50 \%$ dry bulb temperature) of $18^{\circ} \mathrm{C}$ does not guarantee comfort; this is dependent upon many other factors including clothing and activity, hence this is an approximate metric.

Water supplied at $40^{\circ} \mathrm{C}$ is the temperature of a typical shower [39]. The buffer sizes identified from this stage of modelling are the lowest buffer tank volumes (with or without additional PCM modules) that satisfy the two aforementioned criteria.

\footnotetext{
${ }^{2}$ As is normal with an ESP-r simulation, to minimise the impact of initial temperatures on the simulation results, the simulated week was preceded by a 14-day "pre-simulation" period where the performance of the model was solved, but the results were not saved.
} 
Other performance metrics extracted were the heat pump coefficient of performance, its electrical energy consumption and the number of on-off cycles, all of which were affected by the use of thermal buffering and the alteration of the heat pump operating times.

\subsection{Energy, Economic and Environmental Performance}

For the buffer sizes (with and without PCM) identified from the 1-week simulations which maintained comfort and hot water temperatures, a further annual simulation was undertaken. The ASHP technical performance data from these simulations was analysed to determine the heat pump energy use, running costs along with the carbon emissions associated with the electrical energy use of the heat pump. Table 5 shows the on and off-peak prices applied [40].

\section{Table 5}

To quantify the $\mathrm{CO}_{2}$ emissions from the heat pump whilst accounting for the effect of load shifting it was necessary to generate time-varying carbon intensity data using a technique described by Hawkes [34]. Briefly, data on the UK generation-mix for each hour of 2011 was obtained from Elexon [41]. This information along with the assumed carbon intensities for different generation types [40] was then used to calculate the average hourly $\mathrm{CO}_{2}$ intensity $\left(\mathrm{gCO}_{2} / \mathrm{kW}\right)$ for grid electricity for each hour of the year as shown in Figure 7a. Additionally, Figure $7 \mathrm{~b}$ shows the grid carbon intensity variations over the simulated winter week. The simulated heat pump electrical demand over each hour ( $\mathrm{kWh})$ could then be mapped to the appropriate $\mathrm{CO}_{2}$ intensity and so the $\mathrm{CO}_{2}$ emissions $(\mathrm{kg})$ associated with the operation of the heat pump over every hour of the year could be calculated.

Figure 7a

Figure $7 b$

\subsection{Load Shifting a Population of Heat Pumps}

The effect of load shifting on the local, low voltage (LV) network, over several hours with the aid of a PCM-enhanced thermal buffer was analysed on the aggregate demand of a population of 50 similar, detached dwellings. This scenario approximates the situation found in many UK suburban housing estates (e.g. [42]), where the dwellings are of a similar age and type and corresponds to a worst case scenario that amplifies the effect of the electrification of heat and load shifting. The analysis was undertaken over the same cold winter week used to size the buffer tank capacity.

Each dwelling incorporated a retrofitted, buffered heat pump. In order to enact the load shift, the operation of the whole population of heat pumps was constrained to Economy 10 off-peak periods. The resulting aggregate demand for the 50 dwellings was then compared to the case where unbuffered heat pumps were allowed to meet the dwellings' heating demand without operating constraints. The occupancy of the dwellings was predominantly intermittent, with pronounced peaks of electrical and heating activity in the morning and evening.

The load management analysed here involves very substantial load shifts using a relatively crude, tariff-based approach. Consequently, the analysis that follows does not constitute an optimum means of load shifting; however, it does illustrate some of the potential implications of shifting thermal loads over periods of several hours using existing levers such as Economy 10. Substantial load shifting of this type may be required in order to radically re-shape local, domestic demand; though such a high penetration of heat pumps represents a severe test for the LV network.

This study required the use of ESP-r to calculate the heat pump electrical power consumption along with a domestic electricity demand model (DEDM) developed by Richardson et al [43]. The DEDM calculated the matching electrical demand of each household (excluding the heat pump demand). The summation of each dwelling's heat pump electrical demand and the household appliance demand gave the total (real) electrical demand.

Implementing Diversity for Unconstrained Operation 
An important element in the determination of the aggregate demand was to introduce diversity into the individual heat demands. Accordingly, for each dwelling modelled in ESP-r, the total operating time of the heating system, the heating system start/stop time settings and the heating system set point were randomly varied according to statistical distributions provided by Shipworth et al [44]. In their survey of conventional domestic heating operating conditions, Shipworth et al [44] provide estimated data on UK heating system operating times and heating system set points. This estimated data was derived from heating system monitoring and indicated that for a detached house, the mean, aggregate time over which a central heating system was active was approximately 8.7 hours per day with a standard distribution of 1.4.

The study by Shipworth et al. [44] does not provide information on the specific hours over which a heating system would be operational. Consequently, in order to produce specific, diverse operating times for a population of heat pumps, the basic heating system start and stop times outlined for the sizing simulations were each taken as a mean value and assigned a standard deviation. An iterative, multi-dimensional search was then employed to calibrate the four resulting standard deviations such that, when averaged over a large number of runs, the randomly generated heating system operating times produced from these distributions (shown in Table 6) matched the mean heating system operating time distribution observed in [44]. Note this approach explicitly assumes that the majority of dwellings have two distinct heating periods; this is a common assumption in UK domestic energy models such as BREDEM [45].

\section{Table 6}

To provide additional diversity, the thermal buffering for each dwelling was provided by either a $1000 \mathrm{~L}$ hot water or $500 \mathrm{~L}, 50 \%$ PCM-enhanced buffer. Further, the number of dwelling occupants (and subsequent heat gains) were assigned based on household size statistics from the UK office of national statistics [46]. Dwelling infiltration levels were randomly assigned based around the infiltration distributions for thermally improved dwellings provided by Johnston et al [27], and set points were allocated based on the monitored distribution for detached dwellings in [44].

\section{Diversity for Load-Shifted Operation}

For the case of the load-shifted heat pumps, the possible period of operation for each heat pump was constrained to those times dictated by the Economy 10 tariff. It was assumed that end-users would allow their heat pump operating times to be adjusted accordingly. However, the Economy 10 tariff times only define the period within which the heat pump may operate, whether or it does or not is dependent upon the timing of the space heating and hot water demands. Recall, that in the load-shifted system, the space heating and DHW load was met by a circulating pump drawing hot water from the buffer tank. The operating times of the circulating pump (i.e. the times when heat is required by the end user) were subject to the same diversity criteria as outlined previously for the unconstrained, unbuffered heat pump operation. Therefore, whilst the potential operating period of the heat pump is constrained by tariff times, the demand for heat and the operation of the buffered system's hot water circulating pump is subject to diversity.

\section{Domestic Demand Profiles (excluding heat pump demand)}

The corresponding appliance demand profile calculated for each dwelling by the domestic electricity demand model (DEDM) also generated diversity, in that it factors in the different occupant numbers, variations in occupancy timings, and variations in appliance ownership into each profile generated.

Figure 8 shows a single DEDM profile for household electrical appliance demand over 24 hours at 1 minute time resolution. Figure 8 also shows the corresponding 24-hour heat pump demand profile (subject to load shifting) generated by ESP-r again at 1-minute time resolution. The combination of the two time series yields a unique total electrical demand profile for one household. Profiles like these were developed for each detached dwelling variant, the summation of which gave the aggregate demand characteristics for the population of 50 dwellings and heat pumps. 


\section{Results and Discussion}

\subsection{Buffer Tank Size Required for Load Shifting}

Table 7 contrasts the performance of the sensible and PCM-enhanced thermal buffers required to successfully shift heat pump operation to off-peak periods during the simulated winter week. Also shown is the performance of the reference case with no load shifting. A tank size of $500 \mathrm{~L}$, with $50 \%$ of the volume occupied by PCM, enabled effective load shifting without adversely affecting the comfort or availability of hot water to the end-user. Without the inclusion of the PCM, a buffer tank of $1000 \mathrm{~L}$ was required. The performance data shown was derived from the time-series simulation output of the ESP-r model. Example output can be seen in figures 9 and 10, which highlight the operation of the unbuffered heat pump and the heat pump with the PCM-enhanced buffer, respectively over the course of a day. Note however, that the temperature scaling masks the small variation on outside air temperature.

\section{Table 7}

Figure 9 shows the operation of the heat pump when directly coupled in to the space heating and hot water system of the dwelling, with the heat pump initially operating to charge the DHW tank and then cycling to maintain the living space temperature. The figure also illustrates the dynamic nature of the model, with the variation flow and return temperatures, storage temperatures, heat pump output and electrical demand.

Figure 10 shows the effect of buffering and load shifting, with heat pump operating to charge the buffer tank, which is then discharged to meet the dwelling's space heating and hot water demands. The heat pump operation is decoupled from the evolution of the living space and hot water tank outlet temperatures. The discharge of the buffer tank is evident (Figure 10) through the sudden reductions in temperature, as the pump taking hot water from the buffer (shown in Figure 2) first charges the hot water tank and then operates to meet the space heating demand during periods of active occupancy.

\section{Figure 9}

Figure 10

Figure 10 also shows the effect of the of the PCM, with some temperature recovery in the outlet temperature of the buffer tank after the initial morning demand, as the warmer PCM modules heat the surrounding, cooler water.

\subsection{Energy, Economic and Environmental Performance}

Having identified the tank sizes required to deliver effective load shifting from the winter week simulation, full annual simulations were undertaken to assess the energy performance of the load shifted, buffered system. The results are shown in Table 8.

Comparing the buffered to the unbuffered case, there was a clear annual energy penalty associated with the load shift to off-peak periods. With the $500 \mathrm{~L}$, PCM-enhanced tank, the annual energy use was $61 \%$ higher than in the unbuffered case with no load shift. The energy use for the $1000 \mathrm{~L}$ tank was $65 \%$ higher. The reasons for this increase in energy use were as follows.

Firstly, the COP of the buffered heat pumps was lower than the unbuffered case: the addition of the extra heat exchanger in the buffer tank between the ASHP and the heating system means that the temperature at which heat was supplied needed to be greater in order to maintain similar conditions in the dwelling. This is evident when comparing the flow and return temperatures in Figures 9 and 10 , the heat pump outlet temperature is some $5^{\circ} \mathrm{C}$ higher than the case with no buffer and towards the upper end of the modelled heat pump's capabilities. Moreover, the load-shifted ASHP operated during off-peak hours, generally during the evening and early morning when outside air temperatures were lower; this, coupled with the elevated supply temperatures resulted in the 
temperature difference across the heat pump being greater and so the COP was reduced, as is evidenced in the performance characteristics shown in Figure 3. Secondly, whilst the buffer tank in these simulations was well insulated (with a heat loss coefficient of $1 \mathrm{~W} / \mathrm{m}^{2} \mathrm{~K}$ ) it was still subject to parasitic losses not present in the unbuffered case. The impact of parasitic losses is evident in the periods of slow decay of the buffer tank temperature evident in Figure 10. The buffer tank efficiency (i.e. energy input/energy delivered) calculated from the simulations was $84 \%$ for the $1000 \mathrm{~L}$ tank and $92 \%$ for the 500 L PCM-enhanced tank.

It is also worth noting that the annual COP of the buffered, shifted systems is marginally higher than their COP for the simulated winter week; this would be expected as during other periods of the year the ambient air temperature is higher. The annual COP of the unbuffered system is marginally lower than in the winter week. This is due to higher levels of cycling during periods of low load in warmer months offsetting the benefit of higher ambient air temperatures. However, the annual COP of the unbuffered system is still superior to that seen in both of the buffered, load-shifted cases.

Table 8 also shows the calculated $\mathrm{CO}_{2}$ emissions for the unbuffered and buffered, load-shifted heat pumps. With the $2011 \mathrm{UK} \mathrm{CO}_{2}$ intensity shown in Figure 7, load shifting of the heat pump into offpeak periods resulted in increased $\mathrm{CO}_{2}$ emissions, primarily because load shifting increased the heat pump's electrical demand and because the difference in UK grid $\mathrm{CO}_{2}$ intensity between peak and offpeak periods was generally small.

Table 8 shows a pronounced annual cost penalty for the end user from load shifting. The additional electrical demand required for effective load shifting was not adequately compensated for by the price differential between Economy 10 off-peak unit costs and the standard unit cost shown in Table 4. Based on the evidence of these simulations, the off peak-price would need to be approximately $0.0815 \mathrm{f} / \mathrm{kWh}$ (i.e. $62 \%$ of the standard unit electricity cost) before the load shifting became costneutral. The off-peak price is currently $80 \%$ of the of the standard unit price. Note that the running costs shown do not include standing charges.

\subsection{Load Shifting a Population of Heat Pumps}

Two sets of simulations were run over the winter week to gauge the impact of simple, tariff-based load shifting (as exemplified by Economy 10) on the net electrical demand of a hypothetical population of 50 dwellings equipped with heat pumps. One set of simulations was run for 50 detached dwellings equipped with the buffered ASHP system ( $500 \mathrm{~L}$ tank $50 \%$ PCM) subject to load shifting; and one set for 50 dwellings with unbuffered ASHP systems not subject to load shifting. This latter set of simulations was used as the reference case. Each individual simulation used a variant of the detached dwelling model, but with key parameters randomly varied to provide heat load diversity as described previously. The case illustrated here amplifies the potential impact of heat pump load management as it would be expected in most cases that the penetration of heat pumps would be less than $100 \%$.

In the simulations where the operation of the heat pump was unconstrained, the heat pump could operate when the heating control was active during the morning and evening and whenever there was a requirement for space heating or hot water in the dwelling. The time settings for active heating control varied from dwelling to dwelling according to the distributions shown in Table 6.

In the buffered, load-shifting case, the heat pump operation was constrained; the heat pump could operate only within the low-cost electricity periods defined by Economy 10. However, the demand for heat was still subject to diversity. Heat was supplied for space heating and hot water from the buffer tank via a circulating pump - the operating times for this pump were randomly varied between simulations, using the same distributions used for the unconstrained heat pump shown in Table 6.

Figure 11 
Figure 11 shows the net dwelling real power demands with and without heat pump load shifting over a typical 24-hour period during the simulated week.

The plot of the aggregate real electrical demand for the 50 dwellings, when not subject to load shifting, shows distinct morning and evening peaks when the heat pumps are in operation. However, the operation of the heat pumps (like the demand for heat) was spread over several hours during both morning and evening.

Shifting the operation of all of the heat pumps to off-peak periods, as defined by the Economy 10 tariff resulted in new and significantly increased peak demands during the constrained operating periods; particularly in the short, off-peak periods of $13.00 \mathrm{hrs}-16.00 \mathrm{hrs}$ and $20.00 \mathrm{hrs}-22.00 \mathrm{hrs}$, which show limited load diversity. The lack of diversity is due to the short duration of these periods: in both, the majority of the heat pumps modelled need to operate in order to replenish the buffer tank depleted by morning and early evening heat demands. Therefore, an unintentional consequence is that these brief, off-peak periods act to synchronise the population of heat pumps such that the aggregate demand of the dwellings rises to $230 \mathrm{~kW}$, compared to approximately $150 \mathrm{~kW}$ when the operation of the population of heat pumps was not constrained by the load shifting tariff. The same figure shows that if the percentage of heat pumps subjected to the Economy 10 tariff is reduced, so the peak demand reduces.

The tendency of load management to reduce load diversity and produce "undesirable effects" was highlighted by Strbac [47] and similar increases in peak loading were observed by Moreau [10], who examined load shifting of electrical water-heating loads. The results presented here serve as a warning that whilst instruments such as the Economy 10 tariff investigated in this study may beneficial to high-level grid operation they are not necessarily beneficial to the operation of the local electrical network or to individual users.

\section{Conclusions}

To study the ability of phase change material (PCM)-enhanced thermal storage to facilitate effective heat pump load shifting, a model of a typical UK detached dwelling complete with a buffered airsource-heat-pump (ASHP) heating system has been developed on the ESP-r building simulation tool. A series of simulations were then run using a cold UK climate week in which the operation of the heat pump was restricted to off-peak periods.

The simulations indicated that $1000 \mathrm{~L}$ of hot water buffering was required for load shifting to off peak periods. However, augmenting the thermal buffer with 50\% PCM by volume halved the required volume of buffering required to $500 \mathrm{~L}$ without a noticeable deterioration in the space temperatures or hot water temperatures delivered to the end user.

In this case, the simulations highlighted an energy penalty in excess of $60 \%$ associated with the use of PCM-enhanced buffering and load shifting. This was due to a reduction in the COP of the heat pump when operated with thermal buffering, and the introduction of buffer heat losses.

Due to the increased energy use from load shifting and the peculiarities of the time-varying $\mathrm{CO}_{2}$ intensity of the UK grid, $\mathrm{CO}_{2}$ emissions were actually greater when the heat pump demand was load shifted to off-peak periods.

Similarly, applying UK off-peak Economy 10 prices to the load-shifted ASHP energy demand indicated that there was a cost penalty associated with running the heat pump during off peak periods, due primarily to the increased energy requirements.

Simulation of a population of 50 , buffered heat pumps indicated that constraining them to operate only in off peak periods had the potential to substantially increase the peak electrical demand seen on the LV network compared to the case where the heat pumps were unbuffered and their operation was unconstrained. 


\subsection{Limitations of the Study and Future Work}

This study has highlighted some potentially serious consequences associated with heat pump load shifting to off peak periods for the end-user and for electricity network operators. However, these conclusions need to be viewed alongside the limitations of this study as highlighted below.

The energy use of the heat pump was seen to increase in all of the cases simulated where buffering was used. However, whilst the heat pump system modelled here is representative of field trial installations (e.g. [33]), it was not optimised in relation to cost, delivery of both space heating and hot water and alternative building and system configurations are available. For example, hot water could have been delivered directly from the buffer tank, rather than a separate hot water tank. Separating the hot water and space heating functions of the heat pump would allow improvements such as outside air temperature compensation to be implemented. Refinement of the heating system modelled here may reduce the difference in energy demand between the load shifted and non-loadshifted heat pump systems, though it is unlikely that the difference between the two cases could be fully eliminated.

With regards to the space saving achieved through use of the PCM tank, the economic benefits from increased floor area availability must be offset against increased running costs and the capital cost of the PCM tank. As PCM thermal stores are not yet widely available in the UK, along with their costs, such a cost-benefit analysis should be the focus of future research.

In this study both the $\mathrm{CO}_{2}$ emissions and running costs of the buffered, load-shifted heat pump system were seen to be higher than the case with no load shifting. This was a consequence of the specific time-varying carbon intensity seem on the UK network in 2011 and specific off-peak and standard tariffs applied, respectively. As the UK generation mix changes towards 2050, so the timevariations of grid $\mathrm{CO}_{2}$ intensity will inevitably change and so, potentially would the $\mathrm{CO}_{2}$ emissions associated with heat pump load shifting. Additionally, off-peak tariffs could be re-designed and refined to incentivise load shifting and also to minimise the risk of the load synchronisation and consequent high peak demands seen in this study.

Finally, constraining a population of heat pumps to operate only in narrow off-peak periods was seen to increase peak aggregate demand rather than reduce it. Note that, the modelling of the heat pump population control presented here is illustrative of a crude tariff-based approach and does not represent the optimum means of control of populations of electrical devices. For example, Bagdanavicius and Jenkins [6] use an indirect control approach, attempting to control the peak load of a population of heat pumps by altering housing thermostat settings; the same approach is adopted by Wang et al [12]. Additionally, more subtle control may be feasible as more sophisticated heat compressors are integrated into domestic heat pumps, where the compressor output can be proportionally controlled based on the load (e.g. [48]). The heat pump modelled here was equipped with a compressor that could only be operated in on/off mode.

The work presented here does strongly signal that more sophisticated load management strategies than a simple tariff-based approach would be required if load shifting of populations of buffered heat pumps is to bring about the desired reduction in peak demand levels, reduction in carbon emissions, reduction in costs, or synchronisation with renewable generation.

\section{Acknowledgements}

The simulation work described in this article was done with the support of the SUPERGEN Highly Distributed Energy Futures and the Top and Tail Grand Challenge in Energy Networks research consortiums and gratefully acknowledge the funding and support provided by the UK Research Council's Energy Programme under grants EP/G031681/1 and EP/1031707/1 respectively. The authors also wish to acknowledge the assistance of members of IEA ECBCS Annex 54 for their help and useful input to this work.

\section{References}


[1] HM Government. The UK low carbon transition plan - National strategy for climate and, energy. The Stationary Office, London 2009: pp 77.

[2] Palmer J, Cooper I (eds.). Great Britain's Housing Energy Fact File. Department for Energy and Climate Change Publication 2011. URN 11D/866.

[3] DECC, Department for Energy and Climate Change (2012) Energy Consumption in the United Kingdom: DECC Factsheet. 2012. URN 12D/291.

[4] Allen S R, Hammond G P and McManus M C. Prospects for and barriers to domestic microgeneration: A United Kingdom perspective. Applied Energy. 2008; 85; 6: pp. 528-544.

[5] Hewitt, N J. Heat pumps and energy storage - the challenges of implementation. Applied Energy. 2012; 89: pp37-44.

[6] Bagdanavicius A, Jenkins N. Power requirements of ground source heat pumps in a residential area, Applied Energy. 2013; 102: pp591-600.

[7] Hinnells M, Boardman B, Darby S, Killip G, Layberry R. Transforming UK homes: achieving a 60\% cut in carbon emissions by 2050 Proc. European Council for an Energy-Efficient Economy 2007 Panel 5: Energy Efficient Buildings. Available from: http://www.eceee.org/conference_proceedings/eceee/2007/Panel_5/5.356/paper

[8] Lira L, Kelly N J. Impact of residential energy system sizing and control over heat pump's system cost and reliability. Proc. the 2 nd Int. Conf. in Microgeneration Techechnologies. University of Strathclyde. Glasgow. April 4-6; 2011.

[9] P. Luickx, L. Helsen, and W. D'haeseleer. Influence of massive heat-pump introduction on the electricity-generation mix and the GHG effect: Comparison between Belgium, France, Germany and The Netherlands. Renewable \& Sustainable Energy Reviews. 2008; v12; n8: pp. 2140-2158.

[10] Moreau, A. Control Strategy for Domestic Water Heaters during Peak Periods and its Impact on the Demand for Electricity. Energy Procedia. 2011; v12: pp1074-1082.

[11] D. Callaway. Tapping the energy storage potential in electric loads to deliver load following and regulation, with application to wind energy. Energy Conversion and Management. 2009; v50; 9: pp1389-1400.

[12] D.Wang, S.Parkinson, W.Miao, H.Jia, C.Crawford, N.Djilali. Online voltage security assessment considering comfort-constrained demand response control of distributed heat pump systems, Applied Energy. 2012: 96; pp96 104-114.

[13] Hong J, Kelly N J, Thomson M, Richardson I. The influence of thermal storage on microgeneration flexibility. Proc. the 2nd Int. Conf. in Microgeneration Technologies. University of Strathclyde, Glasgow April 2011: pp4-6.

[14] Hong J, Kelly N J, Thomson M, Richardson I. Assessing heat pumps as flexible load. Proc. of the IMECHE Part A: Journal of Power and Energy. 2013: v227;1; pp 30-42.

[15] Arteconi A., Hewitt N.J., Polonara F. Domestic demand-side management (DSM): Role of heat pumps and thermal energy storage (TES) systems. Applied Thermal Engineering. 2013: 51; pp 155165.

[16] Williams, K. Space per person in the UK: A review of densities, trends, experiences and optimum levels. Land Use Policy, 26 (Supple). 2009: pp. 83-92. ISSN 0264-8377

[17] Beyer D and Kelly N J, Modelling the Behaviour of Domestic Micro-Cogeneration under Different Operating Regimes and with Variable Thermal Buffering, Proc. Microgen, National Arts Centre, Ottawa 2008.

662 [18] Economy 10, 2012 http://www.electricityprices.org.uk/economy-10. Accessed 1.11.2012.

663 [19] Clarke J A. Energy Simulation in Building Design. $2^{\text {nd }}$ Ed. Butterworth-Heinemann: Oxford; 2001.

664 [20] Strachan P, Kokogiannakis G and Macdonald I (2008) 'History and Development of Validation

[21] Kelly N J, Cockroft J. Analysis of retrofit air source heat pumps performance: results from detailed simulations and comparison to field trial data, Energy and Buildings. 2011; v43;1: pp239245. 
[22] Padovan R and Manzan M, Development of a stratified tank storage component for ESP-r with embedded phase change material modules, Proc. of the IMECHE Part A: Journal of Power and Energy. 2013; v227;1: pp 53-61.

[23] Cockroft J, Kennedy D, O'Hara M, Samuel A, Strachan P and Tuohy P (2009), 'Development and Validation of Detailed Building, Plant and Controller Modelling to Demonstrate Interactive Behaviour of System Components', Proc. Building Simulation '09, Glasgow, pp 96-103.

[24] Clarke J A, Johnstone C M, Kim J M and Tuohy P G. Energy, Carbon and Cost Performance of Building Stocks: Upgrade Analysis, Energy Labelling and National Policy Development. Advances. in Building Energy Research. 3: Earthscan: London; 2008.

[25]http://www.bre.co.uk/filelibrary/accreditation/scheme_standards/SAP_2009_9-

91_Appendix_S_January_2012.pdf. Accessed 27.11.2013.

[26] BRE The Government's Standard Assessment Procedure for Energy Rating of Dwellings, BRE Report. 2009. Available from: http://www.bre.co.uk/filelibrary/SAP/2009/SAP-2009_9-90.pdf Accessed 24.05.2013.

[27] Johnston D, Wingfield J, Bell M. Airtightness of buildings-towards higher performance. Interim report D1. 2004. Available online: Centre for the built Environment, Leeds Metropolitan University. www.leedsmet.ac.uk/as/cebe/projects/airtight/airtight_final_report.pdf Accessed 23.05.2013

[28] http://discover.ukdataservice.ac.uk/series/?sn=2000054 Accessed 26.05.2013.

[29] Dowson M, Poole A, Harrison D, Susman G, Domestic UK retrofit challenge: Barriers incentives and current performance leading into the Green Deal, Energy Policy, 50, 2012, pp 294-305

[30] Galvin R and Sunnika-Blank M, Including fuel price elasticity of demand in net present value and payback time calculations of thermal retrofits: Case study of German dwellings, Energy and Buildings, 50, 2012, pp219-228.

[31] Jordan U and Vajen K, 2005. DHWCALC: Program to Generate Domestic Hot Water Draws with Statistical Means for User Defined Conditions, Proc. ISES Solar World Congress, Orlando, US.

[32] Knight I, Ribberink H (eds.). European and Canadian non-HVAC Electric and DHW Load Profiles for Use in Simulating the Performance of Residential Cogeneration Systems, A Report of Subtask A of FC+COGEN-SIM The Simulation of Building-Integrated Fuel Cell and Other Cogeneration Systems, Annex 42 of the International Energy Agency Energy Conservation in Buildings and Community Systems Programme. Natural Resources Canada, Ottawa, 2007.

[33] Dunbabin P and Wickins C, Detailed analysis from the first phase of the Energy Saving Trust's heat pump field trial, Department for Energy and Climate Change (DECC) Report, URN12D/018.

[34] UK Health and Safety Executive, Legionnaires' disease. The control of legionella bacteria in water systems: Approved Code of Practice and guidance L8, HSE publications, 2000.

[35] Energy Saving Trust, Solar water heating systems - guidance for professionals, conventional indirect models, Guide CE131, EST publication, 2006.

[36] PCM Products, 2012. http://www.pcmproducts.net/Phase_Change_Material_Products.htm. Accessed 30.10.2012.

[37] National Grid 2012. http://www.nationalgrid.com/ uk/Electricity/Data/Demand+Data/ Jan-July Accessed 22.11.2012.

709 [38] Fanger P. O. Thermal Comfort, McGraw-Hill; New York: 1970.

[39] Lawrence J C, Bull J P. Thermal Conditions Which Cause Skin Burns, Eng. in Medicine. 1976; v5 (5): pp61-63.

[40] Hawkes A. D., 2010. Estimating marginal $\mathrm{CO}_{2}$ emissions rates for national electricity systems, Eng. Policy. 2010; 38: pp5977-5987.

[41] Elexon, 2012. www.elexon.co.uk. Accessed 10.12.2012.

[42] Thomson M, Infield D, Impact of widespread photovoltaics generation on distribution systems, J of Renew. Power Gen. 2007; v1; 1: pp33-40.

[43] Richardson I, Thompson M, Infield D, Clifford C (2010), Domestic electricity use: A highresolution energy demand model. Eng. and Build. 2010; 42; 10: pp 1878-1887.

[44] Shipworth, M., Firth, S. K. , Gentry, M. I., Wright, A. J., Shipworth, D. T. and Lomas, K. J. Central 
721 [45] Shorrock L D, A guide to the development of BREDEM, Building Research Establishment 722 Publication, 1995

723 [46] ONS, Office for National Statistics, Families and Households 2012. http://www.ons.gov.uk/ons/dcp171778_284823.pdf (Accessed 01/02/2013)[47] Strbac G, Demand side management: benefits and challenges, Eng. Policy, 36. 2008. pp 4419-4426. [48] Lee C K, Dynamic performance of ground-source heat pumps fitted with frequency inverters for part-load control, Applied Energy, 87, 2010 pp3507-3513. 
Figure 1 geometric wireframe view of the typical UK detached dwelling ESP-r model.

Figure 2 Heat pump COP and heat output vs. ambient temperature.

Figure 3a The modelled heating system supplied by the ASHP (with no buffer tank).

Figure $3 b$ The modelled heating system supplied by the ASHP (with PCM-enhanced buffer tank).

Figure 4 Stochastic hot water draw profile for the simulated winter week.

Figure 5 Detail of buffer tank with integrated phase change modules.

Figure 6 Reference case and load shifted heat pump operating hours.

Figure 7a hourly UK grid average carbon intensity (g/kWh) for 2011.

Figure $7 b$ hourly UK grid average carbon intensity (g/kWh) for modelled winter week.

Figure 8 combined heat pump and household appliance demand over 24 hours.

Figure 9 Temperatures and heat pump electrical demand with no buffering and no load shift.

Figure 10 Temperatures and heat pump electrical demand with load shifting and buffering.

Figure 11 effect of load shifting of all heat pumps on the aggregate demand of 50 dwellings.

Tables

Table 1 characteristics of the main building elements.

\begin{tabular}{|c|c|c|c|}
\hline Fabric element & Construction Details & $\begin{array}{l}\text { 'U'-value } \\
\left(W / m^{2} K\right)\end{array}$ & $\begin{array}{l}\text { Area } \\
\left(\mathrm{m}^{2}\right)\end{array}$ \\
\hline Glazing & $\begin{array}{l}6 \mathrm{~mm} \text { glass/ } 12 \mathrm{~mm} \text { air gap/ } 6 \mathrm{~mm} \\
\text { glass }\end{array}$ & 3.3 & 24 \\
\hline External walls & $\begin{array}{l}110 \mathrm{~mm} \text { brick } / 60 \mathrm{~mm} \text { cavity fill } / 110 \\
\mathrm{~mm} \text { block/ } 10 \mathrm{~mm} \text { gap/ } 13 \mathrm{~mm} \\
\text { plasterboard }\end{array}$ & 0.37 & 134 \\
\hline Ground floor & $\begin{array}{l}300 \mathrm{~mm} \text { insulation/ } 18 \mathrm{~mm} \\
\text { flooring/10mm carpet + underlay }\end{array}$ & 0.09 & 68 \\
\hline Upper floor ceiling & $\begin{array}{l}300 \mathrm{~mm} \\
\text { plasterboard }\end{array}$ & 0.13 & 68 \\
\hline \multicolumn{4}{|c|}{ Additional Information } \\
\hline & \multicolumn{2}{|c|}{ Total building floor area } & $136 \mathrm{~m}^{2}$ \\
\hline & \multicolumn{2}{|c|}{ Total building volume } & $448 \mathrm{~m}^{3}$ \\
\hline & \multicolumn{2}{|c|}{ Total heated volume } & $326 \mathrm{~m}^{3}$ \\
\hline & \multicolumn{2}{|c|}{ Average air change rate (air-changes-per-hour) } & 0.5 \\
\hline
\end{tabular}

Table 2 key calibrated parameters and equations used with the ASHP model.

\begin{tabular}{|l|c|l|c|}
\hline Parameter & Value & Parameter & Value \\
\hline Effective mass M (kg) & 110.00 & $\begin{array}{l}\text { Maximum ASHP inlet temperature } \mathrm{T}_{\mathrm{r}} \\
(\max )\left({ }^{\circ} \mathrm{C}\right)\end{array}$ & 65 \\
\hline Effective mass specific heat $\bar{c}(\mathrm{~J} / \mathrm{kgK})$ & 3700.0 & $\begin{array}{c}\text { Nominal water return temperature } \\
\operatorname{Tr}(\text { nom })\left({ }^{\circ} \mathrm{C}\right)\end{array}$ & $45-55$ \\
\hline Heat loss modulus UA $(\mathrm{W} / \mathrm{K})$ & 15.000 & Nominal water return dead band $\left({ }^{\circ} \mathrm{C}\right)$ & 5 \\
\hline
\end{tabular}




\begin{tabular}{|c|c|c|c|}
\hline ASHP HW pump rating $P_{p}(W)$ & 95.000 & $\begin{array}{l}\text { Defrost cycle ambient temperature } \\
\text { trigger }\left({ }^{\circ} \mathrm{C}\right)\end{array}$ & 5.5 \\
\hline $\begin{array}{l}\text { Mass flowrate at rated pump power } \\
\dot{m}(t) c_{w}(\mathrm{~kg} / \mathrm{s})\end{array}$ & 0.26 & Defrost cycle RH trigger (\%) & 60 \\
\hline Evaporator Fan power $\mathrm{P}_{\mathrm{ef}}(\mathrm{W})$ & 220.0 & ASHP controller power $\mathrm{P}_{\text {co }}(\mathrm{W})$ & 10 \\
\hline \multicolumn{4}{|c|}{$\begin{array}{l}\text { ASHP COP: } \\
\text { COP }=0.0005 \times\left(T_{r}-T_{\infty}\right)^{2}-1.022 \times\left(T_{r}-T_{\infty}\right)+6.3972(1)\end{array}$} \\
\hline \multicolumn{4}{|l|}{$\begin{array}{l}\text { Compressor power demand (W): } \\
P_{c}=1000 \times 2.002 e^{\left(T_{r}-T_{\infty}\right)}(2)\end{array}$} \\
\hline \multicolumn{4}{|c|}{$\begin{array}{l}\text { ASHP heat exchanger energy balance (J): } \\
M \bar{c} \frac{d T_{f}}{d t}+\dot{m} c_{w} T_{f}=P \times C O P-U A\left(T_{f}-T_{c}\right)+\dot{m} c_{w} T_{r}(3)\end{array}$} \\
\hline \multicolumn{4}{|l|}{ Time between defrost cycles (s): } \\
\hline \multicolumn{4}{|c|}{$\Delta t_{d}=0.06 T_{\infty}^{3}+1.23 T_{\infty}^{2}-25.1 T_{\infty}+0.234 T_{\infty} R H+0.0551 R H^{2}-11.6 R H+629(4)$} \\
\hline \multicolumn{4}{|c|}{$t_{d}=\frac{3.6 \times 10^{6}}{P \times C O P}\left(-0.000311 T_{\infty}^{3}-0.00489 T_{\infty}^{2}+1.65 \times 10^{-8} \Delta t_{d}^{3}-1.05 \times 10^{-5} \Delta t_{d}^{2}+0.00226 \Delta t_{d}+0.163\right)(5)$} \\
\hline
\end{tabular}

Table 3 data used with DHW model to calculate hot water demand (adapted from [26]).

\begin{tabular}{|l|l|l|l|l|}
\hline Appliance Draws & Basins & Appliances & Baths & Showers \\
\hline Nominal flow rate (I/min) & 1 & 6 & 12 & 8 \\
\hline Flow Std. deviation & 2 & 2 & 0.0167 & 0.05 \\
\hline Percentage of total draw (\%) & 14 & 36 & 10 & 40 \\
\hline Duration (mins) & 1 & 1 & 10 & 4 \\
\hline \multicolumn{5}{|l}{} \\
\hline Distribution of Draws & \multicolumn{5}{|l}{} & & \\
\hline Time & $0-6 \mathrm{hrs}$ & $6 \mathrm{hrs}-9 \mathrm{hrs}$ & $\begin{array}{l}9 \mathrm{hrs}- \\
17 \mathrm{hrs}\end{array}$ & $\begin{array}{l}17 \mathrm{hrs} \\
24 \mathrm{hrs}\end{array}$ \\
\hline Percentage of total draws (\%) & $10 \%$ & $50 \%$ & $10 \%$ & $30 \%$ \\
\hline
\end{tabular}

Table 4 Selected characteristics of the phase change material [36].

\begin{tabular}{|l|r|}
\hline Latent heat $\mathrm{J} / \mathrm{kg}$ & 210,000 \\
\hline Melting temperature ${ }^{\circ} \mathrm{C}$ & 48 \\
\hline $\mathrm{c}$ solid J/kgK & 2410 \\
\hline $\mathrm{c}$ liquid J/kgK & 2410 \\
\hline$\rho$ solid $\mathrm{kg} / \mathrm{m}^{3}$ & 1600 \\
\hline$\rho$ liquid $\mathrm{kg} / \mathrm{m}^{3}$ & 1666 \\
\hline
\end{tabular}




\begin{tabular}{|l|r|}
\hline$k$ conductivity solid $\mathrm{W} / \mathrm{mK}$ & 0.45 \\
\hline$k$ conductivity liquid $\mathrm{W} / \mathrm{mK}$ & 0.45 \\
\hline
\end{tabular}

752

753

754

Table 5 Economy 10 on and off peak energy costs [18].

\begin{tabular}{|l|c|c|}
\hline Tariff & fGBP per kWh & fGBP per kWh \\
\hline $\begin{array}{l}\text { Standard unit cost } \\
\text { (for unbuffered ASHP with no } \\
\text { load shift) }\end{array}$ & \multicolumn{2}{|c|}{0.1308} \\
\hline $\begin{array}{l}\text { Economy 10 unit costs } \\
\text { (for buffered ASHP under } \\
\text { load-shift) }\end{array}$ & 0.1817 & 0.1053 \\
\hline
\end{tabular}

Table 6 Heating systems start/stop characteristics used in multiple dwelling study (derived from $[27,44,46]$ ).

\begin{tabular}{|c|c|c|c|}
\hline Start am (hrs) & Std. Dev. & Stop am (hrs) & Std. Dev. \\
\hline 6.0 & 1.08 & 9.0 & 1.4 \\
\hline Start pm (hrs) & Std. Dev. & Stop pm (hrs) & Std. Dev. \\
\hline 16.0 & 1.05 & 23.0 & 2.28 \\
\hline Set point $\left(^{\circ} \mathrm{C}\right)$ & Std. Dev. & Infiltration & Std. Dev. \\
\hline 21 & 2.5 & 0.45 & 0.13 \\
\hline
\end{tabular}

Table 7 System performance and size of buffering required for effective load shifting (winter week).

\begin{tabular}{|l|c|c|c|}
\cline { 2 - 4 } \multicolumn{1}{c|}{} & $\begin{array}{c}\text { Unbuffered no } \\
\text { load shift } \\
\text { (reference) }\end{array}$ & $\begin{array}{c}1000 \text { L hot water } \\
\text { buffer } \\
\text { off-peak operation }\end{array}$ & $\begin{array}{c}\text { PCM-enhanced buffer } \\
500 \mathrm{~L}+50 \% \text { PCM } \\
\text { off-peak operation }\end{array}$ \\
\hline Average living room temperature $\left({ }^{\circ} \mathrm{C}\right)$ & 20.9 & 21.2 & 21.0 \\
\hline Average buffer temperature $\left({ }^{\circ} \mathrm{C}\right)$ & N/A & 47.9 & 48.4 \\
\hline Average DHW temperature $\left({ }^{\circ} \mathrm{C}\right)$ & 44.6 & 44.2 & 43.9 \\
\hline Average ASHP COP $(-)$ & 3.04 & 2.44 & 2.37 \\
\hline ASHP heat output $(\mathrm{kWh})$ & 204.5 & 276.0 & 247.3 \\
\hline ASHP electrical energy $(\mathrm{kWh})$ & 69.5 & 115.2 & 106.4 \\
\hline ASHP cycles - & 127 & 41 & 65 \\
\hline
\end{tabular}

